\title{
Chemo-Enzymatic Synthesis of Chiral Fluorine-Containing Building Blocks
}

\author{
Richard H. Blaauw ${ }^{a \star}$, Denis R. IJzendoorn ${ }^{a}$, Jozef G.O. Cremers ${ }^{b}$, Floris P.J.T. Rutjes ${ }^{b}$, \\ Quirinus B. Broxterman ${ }^{\mathrm{C}}$, and Hans E. Schoemaker ${ }^{\mathrm{C}}$
}

\begin{abstract}
Two complementary strategies for the synthesis of optically active fluorine-containing building blocks have been probed. The first strategy involves either the enzymatic resolution of fluorinated $\alpha, \alpha$-disubstituted- $\alpha$-amino acid amides, or the asymmetric hydrogenation of fluorinated dehydroamino acids. The second strategy involves the transition metal-catalyzed introduction of fluorine-containing substituents onto olefin- or acetylene-containing $\alpha-\mathrm{H}-\alpha$-amino acids. These amino acids in turn are made optically active by enzymatic resolution of the corresponding amides.
\end{abstract}

Keywords: Asymmetric hydrogenation - Chiral building blocks · Enzymatic resolution · Fluorinated amino acids · Transition metal catalysis

\section{Introduction}

The facile stereospecific synthesis of a variety of multifunctional building blocks is an important component of the drug discovery toolbox. More specifically, technology for the preparation of fluorine-containing building blocks forms a powerful addition to this toolbox. To this end, Chiralix aims at the development of novel technologies for the efficient synthesis of such chiral, densely functionalized compounds by a synergistic combination of advanced organic synthesis, homogeneous transition metal catalysis, and biocatalysis. This is done in close collaboration with the academic research group of Prof. Floris Rutjes at the University of Nijmegen (NL), as well as

\footnotetext{
${ }^{\text {*Correspondence: }}$ Dr. R.H. Blaauw ${ }^{a}$

aChiralix B.V.

Toernooiveld 100

NL-6525 EC Nijmegen, The Netherlands

Tel.: + 31243652194

Fax: + 31243653393

E-Mail: richard.blaauw@chiralix.com

${ }^{b}$ Department of Organic Chemistry

University of Nijmegen

Toernooiveld 1

NL-6525 ED Nijmegen

'DSM Pharma Chemicals

Advanced Synthesis, Catalysis and Development

P.O. Box 18

NL-6160 MD Geleen
}

with DSM Pharma Chemicals in Geleen (NL).

This paper describes some of the recent efforts of Chiralix and its partners in the development of novel methodologies for the chemo-enzymatic preparation of chiral fluorine-containing building blocks.

\section{Two Complementary Approaches}

In order to arrive at the desired chiral fluorinated compounds we envisaged two possible strategies, depicted in Fig. 1, either one of which should give access to both enantiomerically pure forms of a given building block. The first strategy (counterclockwise in Fig. 1) would be to introduce the desired fluorinated group(s) into a racemic or prochiral substrate, followed by an asymmetric transformation to obtain the molecule in enantiomerically pure form. The second strategy involves the asymmetric transformation of a non-fluorinated building block and subsequent installation of the fluorinated group(s) onto the enantiomerically pure material.

In principle, these two strategies are complementary since they enable us to choose whether the fluorous substituent should be introduced prior to or during the diversification process. Depending on the substitution pattern and complexity of the desired building block, one of the two strategies could prove most advantageous and we therefore set out to probe both pathways.

\section{The First Strategy}

One of our core chiral competences is the enzymatic resolution of amino acid amides by hydrolytic enzyme systems (Fig. $2)$. In general, these enzymes convert Lamino acid amides to the corresponding $\mathrm{L}^{-}$ amino acids, while leaving the D-amino acid amides untouched. Over the last few years a set of microorganisms containing highly stereoselective aminopeptidases and amidases have been identified, all exhibiting their own specific substrate tolerance [1]. The aminopeptidase present in Pseudomonas putida ATCC 12633 was shown to give excellent results in the hydrolysis of $\alpha-\mathrm{H}-\alpha$-amino acid amides, with a wide variety of amino acid side chains [2]. For the resolution of $\alpha, \alpha$-disubstituted- $\alpha$ amino acid amides, whole cells of $M y$ cobacterium neoaurum proved to be the biocatalyst of choice [3], whereas Ochrobactrum anthropi whole cells could be applied in a whole range of resolutions, including those of $\alpha-\mathrm{H}-\alpha$-hydroxy carboxylic acids [4].

In collaboration with the group of Prof. Burger in Leipzig (Germany) a resolution protocol was developed for fluorinated $\alpha, \alpha$-disubstituted- $\alpha$-amino acid amides, using the amidase from Mycobacterium neoaurum. As can be seen from the results of these enzymatic conversions depicted in Table 1, the enzyme performed very well with the three substrates that were investigated. The astonishing discriminatory power of the amidase becomes evident from the 


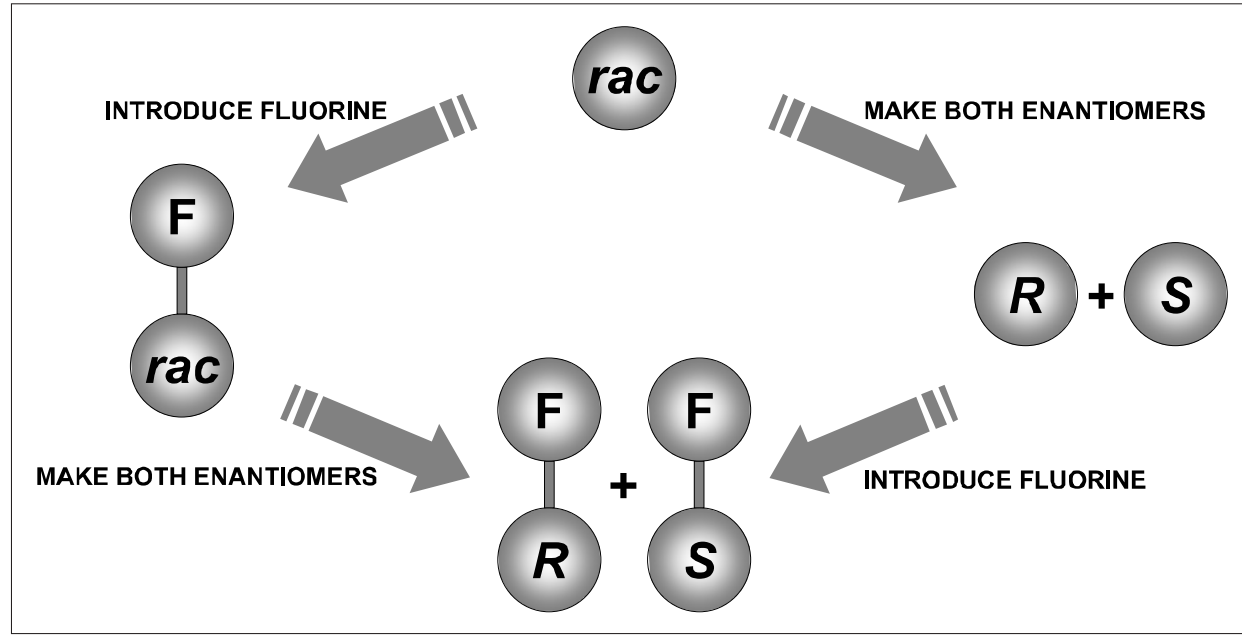

Fig 1. Two complementary strategies for the preparation of enantiomerically pure fluorine-containing building blocks

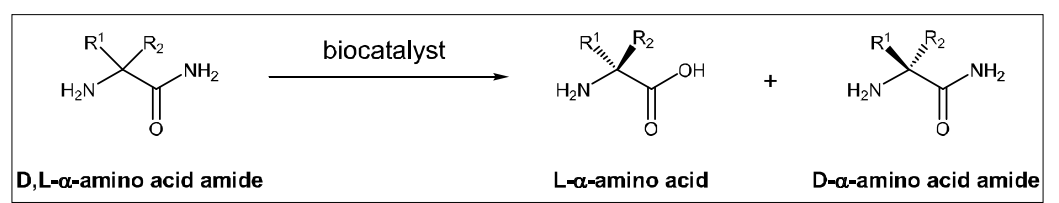

\begin{tabular}{|c|c|}
\hline D,L- $\alpha$-amino acid amide & L- $\alpha$-amino acid \\
\hline Pseudomonas putida & $\alpha-H$ - $\alpha$-amino acids \\
\hline Mycobacterium neoaurum & $\alpha, \alpha$-disubstituted-a-amino acids \\
\hline Ochrobactrum anthropi & $\begin{array}{l}\alpha-H \text { - } \alpha \text {-amino acids } \\
\alpha, \alpha \text {-disubstituted-a-amino acids } \\
N \text {-hydroxy- } \alpha-H \text { - } \alpha \text {-amino acids } \\
\alpha-H \text { - } \alpha \text {-hydroxy carboxylic acids }\end{array}$ \\
\hline
\end{tabular}

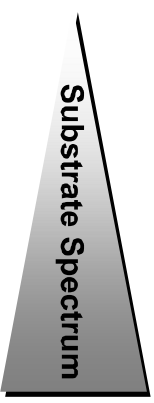

Fig 2. A broad range of amino acid amides can be efficiently hydrolyzed with excellent enantioselectivity by three different microorganisms striking result with the $\alpha$-methyl- $\alpha$-trifluoromethyl substituted amide (entry 1 ), where the enzyme is able to distinguish perfectly between two sterically very similar substituents. Upon facile separation of the $(R)-$ acid and the remaining $(S)$-amide, followed by chemical hydrolysis of the amide, also the $(S)$-amino acid was obtained (ee $>99 \%)$. The functional groups present in such $\alpha, \alpha$-disub- stituted amino acids offer ample opportunities for further diversification.

A totally different approach to target enantiomerically pure fluorinated amino acids is the asymmetric hydrogenation of lent results in the rhodium-catalyzed preparation of amino acid derivatives were obtained by using MonoPhos (Scheme 1), a dehydroamino acid derivatives [5]. Excel-

Table 1. Enzymatic resolutions of fluorinated $\alpha, \alpha$-disubstituted- $\alpha$-amino acid amides

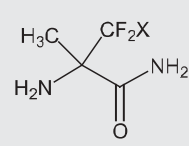

(rac)-amide

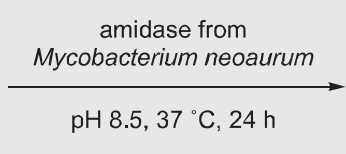

Conversion

$50 \%$

$51 \%$

$51 \%$

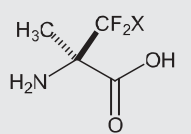

(R)-acid<smiles>[X][C@](C)(N)C(N)=O</smiles>

(S)-amide

$\begin{array}{rrrrrr}\text { Entry } & \mathbf{X} & \text { Conversion } & \text { ee }(R) \text {-acid } & \text { ee }(S) \text {-amide } & \text { E value } \\ 1 & \mathbf{F} & \mathbf{5 0 \%} & \mathbf{9 6 \%} & >\mathbf{9 9 \%} & >\mathbf{1 8 3} \\ 2 & \mathrm{Cl} & 51 \% & 95 \% & >99.5 \% & >200 \\ 3 & \mathrm{Br} & 51 \% & 95 \% & >99.5 \% & >200\end{array}$

novel proprietary monodentate ligand developed by the group of Prof. Ben Feringa (University of Groningen, The Netherlands) [6]. This air and moisture stable phosphoramidite ligand can be synthesized in a single step from cheap commercially available materials and is an order of magnitude cheaper than currently available bisphosphine ligands. For the preparation of the required dehydrophenylalanine substrates for the asymmetric hydrogenation reactions, Heck couplings between fluorine-substituted arylbromides and methyl 2-acetylaminoacrylate were employed (Scheme 2). Interestingly, these reactions could be performed with very low catalyst loadings, i.e. down to $0.05 \mathrm{~mol} \%$, and only afforded the $Z$-isomers of the products. When conducting the asymmetric hydrogenation experiments, it was gratifying to find that the rhodium-MonoPhos complex performed generally well, as can be seen from the results depicted in Table 2. In all cases the reactions proceeded with high enantioselectivities and the products were obtained in quantitative yields.

With these results in hand we now turned our attention to the second strategy, in which first the enantiomerically pure building blocks were prepared and subsequently fluorine-containing substituents were introduced.

\section{The Second Strategy}

The preparation of the required enantiomerically pure building blocks again was based on the enzymatic resolution of amino acid amides, in this case non-fluorinated $\alpha$ $\mathrm{H}-\alpha$-amino acid amides. It had already been shown that the aminopeptidase present in Pseudomonas putida could be used very effectively for the resolution of such amino acids (vide supra). The enzyme proved to be tolerant to a wide variety of amino acid amides, including those with unsaturated side-chains such as olefins, acetylenes and allenes [7]. Since such unsaturations allow various transition metalcatalyzed functionalizations, we envisaged to use these handles for the introduction of the fluorinated substituents.

In literature, the palladium-catalyzed introduction of fluoroalkyl chains onto alkenes has been demonstrated [8]. However, the olefins used were all rather simple and did not contain the intrinsic dense functionalization of unsaturated amino acids. Therefore, we decided to investigate the reaction circumstances, in order to determine whether these conditions were tolerant to the functional groups present in the amino acid substrates. As can be seen from the results depicted in Table 3, a variety of fluoroalkyl chains could be successfully introduced via this method. Everything from 

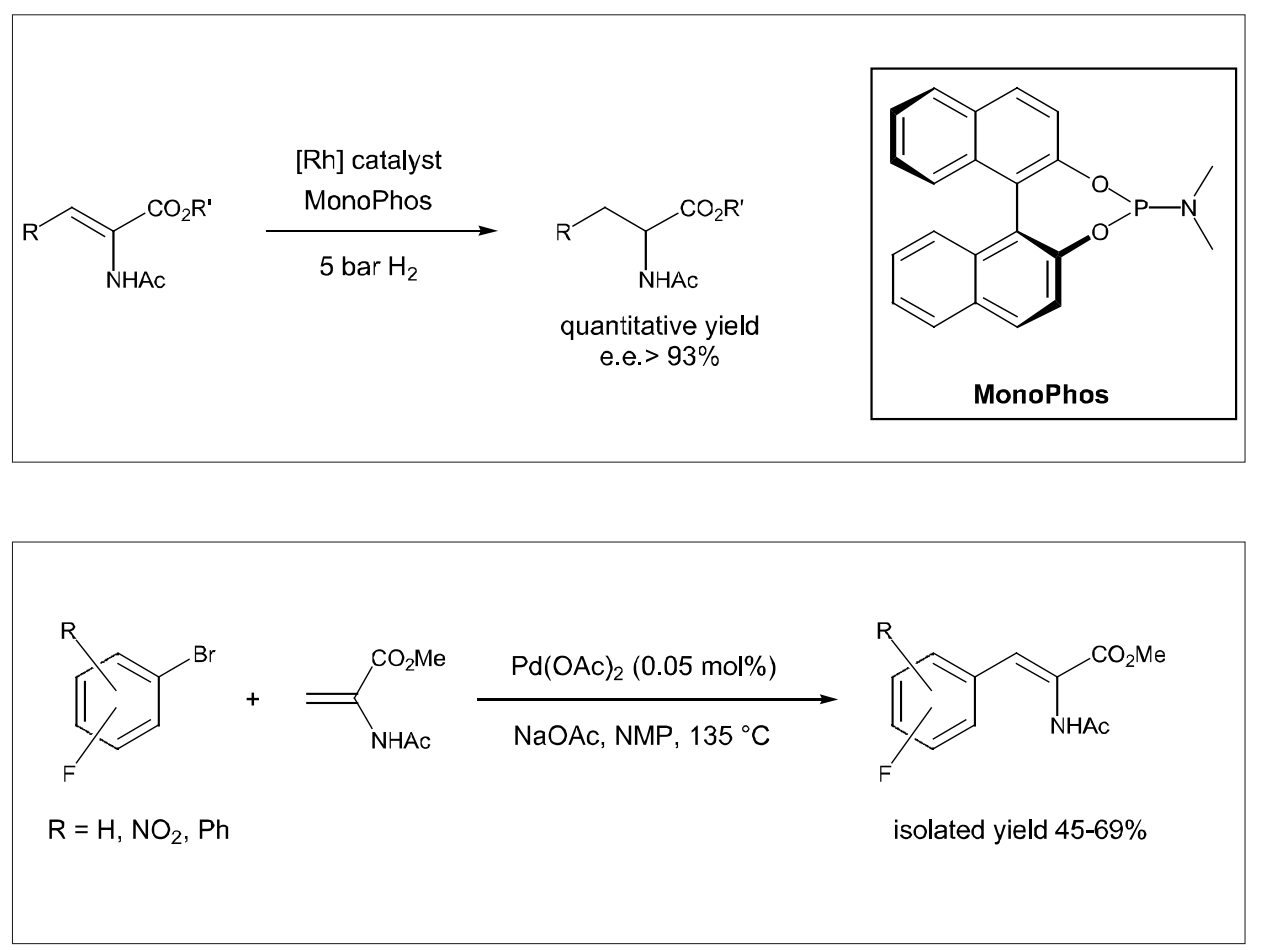

Table 2. Preparation of fluorinated phenylalanine derivatives via asymmetric hydrogenation
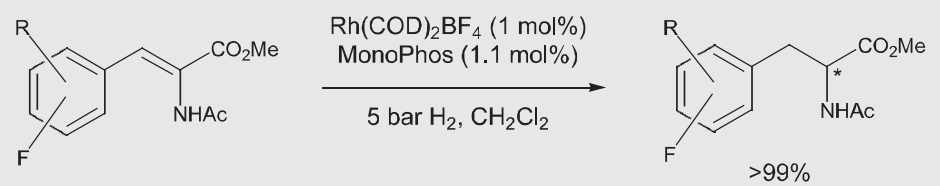

$\begin{array}{ccccc}\text { Entry } & \mathrm{R} & \text { F-position } & \text { Time [min.] } & \text { ee } \\ 1 & \mathrm{H} & 2 & 25 & 95 \% \\ 2 & \mathrm{H} & 3 & 30 & 95 \% \\ 3 & \mathrm{H} & 4 & 15 & 95 \% \\ 4 & 3-\mathrm{NO}_{2} & 4 & 120 & 95 \% \\ 5 & 4-\mathrm{Ph} & 3 & 25 & 93 \%\end{array}$

Table 3. Palladium-catalyzed addition of fluoroalkyl chains onto olefinic amino acids<smiles>C=CCC(NC)C(C)=O</smiles>

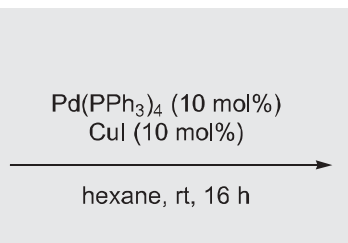

$\mathrm{Cn}_{\mathrm{F} 2 \mathrm{n}+1} \mathrm{I}$

iso- $\mathrm{C}_{3} \mathrm{~F}_{7}$

$\mathrm{C}_{4} \mathrm{~F}_{9} \mathrm{I}$

$\mathrm{C}_{6} \mathrm{~F}_{13} \mathrm{I}$

$\mathrm{C}_{6} \mathrm{~F}_{17} \mathrm{I}$

$\mathrm{CF}_{3} \mathrm{I}$

tert- $\mathrm{C}_{4} \mathrm{~F}_{9}$

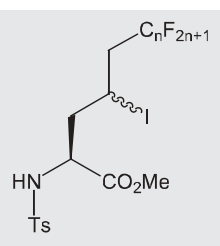

Yield

$90 \%$

$92 \%$

$96 \%$

$96 \%$

$10 \%$

$0 \%$
Scheme 2. Preparation of dehydrophenylalanine substrates via Heck reactions

Scheme 1. Rhodium-catalyzed asymmetric hydrogenations using MonoPhos

perfluoro-iso-propyl iodide to perfluorooctyl iodide reacted smoothly to give the anticipated fluorinated products (entries 1-5). However, the use of trifluoromethyl iodide resulted in a very poor conversion and only afforded the product in a low yield. Even more disappointing was the attempt with perfluoro-tert-butyl iodide, which did not give rise to the expected product at all. Nonetheless, the fluorinated products that had been formed could be successfully de-iodinated, via hydrogenation over palladium on carbon, as exemplified in Scheme 3.

Another literature example of the introduction of fluorinated chains onto unsaturated moieties, involved the zinc-catalyzed addition of perfluoroalkyl iodides onto acetylenes [9]. Again this example involved only relatively unfunctionalized acetylenes, thus we studied the utility of this method in the case of our amino acid substrates. Gratifyingly, the reaction between perfluorobutyl iodide and a suitably protected propargylglycine derivative, mediated by a catalytic amount of zinc powder and a catalytic amount of trifluoroacetic acid, proceeded very smoothly to give the fluorinated olefinic product in a good yield (Scheme 4). The vinyl iodide moiety that results from this reaction provides a convenient handle for further derivatization, since it can be used in a multitude of transition metal-catalyzed cross coupling reactions.

\section{Conclusions}

We have demonstrated two complementary strategies for the synthesis of optically 
<smiles>CC(=O)NC(C[C@@H](I)CC(F)(F)C(F)(F)F)C(=O)O</smiles>
$\underset{\mathrm{Et}_{3} \mathrm{~N}, \mathrm{PdOAc}, \mathrm{rt}, 4 \mathrm{~h}}{\longrightarrow}$<smiles>CNC(CCCC(F)(C(F)(F)F)C(F)(F)F)C(C)=O</smiles>

$99 \%$<smiles>C#CCC(NC)C(C)=O</smiles>

$\mathrm{C}_{4} \mathrm{~F}_{9} \mathrm{I}(2$ equiv.) $\mathrm{Zn}(10 \mathrm{~mol} \%)$

TFA (20 mol\%)

$\mathrm{CH}_{2} \mathrm{Cl}_{2}, \mathrm{rt}, 16 \mathrm{~h}$

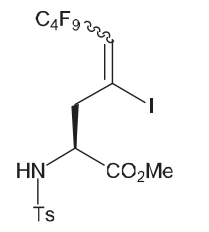

cross coupling

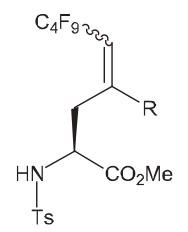

$80 \%(E / Z=4: 1)$

\section{Scheme 3. Reductive removal of the iodide}

Scheme 4. Zinc-catalyzed addition of perfluorobutyl iodide to an acetylenic amino acid active fluorine-containing building blocks. The first strategy involves either the enzymatic resolution of fluorinated $\alpha, \alpha$-disubstituted- $\alpha$-amino acid amides, or the asymmetric hydrogenation of fluorinated dehydroamino acids. The second strategy involves the transition metal-catalyzed introduction of fluorine-containing substituents onto enantiomerically pure unsaturated $\alpha-\mathrm{H}$ - $\alpha$-amino acids, which in turn can be prepared by enzymatic resolution of the corresponding amides. Palladium catalysis allows the introduction of fluoroalkyl chains onto olefinic amino acids, whereas acetylenic amino acids can be fluoroalkylated by means of zinc catalysis.

The two complementary strategies allow maximum flexibility, since they enable the strategic choice, whether the fluorous substituent should be introduced prior to or during the diversification process. Depending on the substitution pattern and complexity of the desired building block, one of the two approaches could prove most advantageous.

Received: December 18, 2003

[1] a) T. Sonke, B. Kaptein, W.H.J. Boesten, Q.B. Broxterman, J. Kamphuis, F. Formaggio, C. Toniolo, F.P.J.T. Rutjes, H.E. Schoemaker, in 'Stereoselective Biocatalysis', Ed. R.N. Patel, Marcel Dekker, New York, 2000, p. 23; b) H.E. Schoemaker, W.H.J. Boesten, Q.B. Broxterman, E.C. Roos, B. Kaptein, W.J.J. van den Tweel, J. Kamphuis, F.P.J.T. Rutjes, Chimia 1997, 51, 308; c) H.E. Schoemaker, W.H.J. Boesten, B. Kaptein, E.C. Roos, Q.B. Broxterman, W.J.J. van den Tweel, J.
Kamphuis, Acta Chem. Scand. 1996, 50, 225.

[2] a) V.H.M. Elferink, D. Breitgoff, M. Kloosterman, J. Kamphuis, W.J.J. van den Tweel, E.M. Meijer, Recl. Trav. Chim. Pays-Bas 1991, 110, 63; b) W.H.J. Boesten, German Patent DE 2526594, 1976.

[3] B. Kaptein, W.H.J. Boesten, Q.B. Broxterman, P.J.H. Peters, H.E. Schoemaker, J. Kamphuis, Tedrahedron: Asymmetry 1993, 4, 1113.

[4] W.J.J. van den Tweel, T.J.G.M. van Dooren, P.H. de Jonge, B. Kaptein, A.L.L Duchateau, J. Kamphuis, Appl. Microbiol. Biot. 1993, 39, 296.

[5] a) M. van den Berg, A.J. Minnaard, R.M. Haak, M. Leeman, E.P. Schudde, A. Meetsma, B.L. Feringa, A.H.M. de Vries, C.E.P. Maljaars, C.E. Willans, D. Hyett, J.A.F. Boogers, H.J.W. Henderickx, J.G. de Vries, Adv. Synth. Catal. 2003, 345, 308; b) M. van den Berg, R.M. Haak, A.J. Minnaard, A.H.M. de Vries, J.G. de Vries, B.L. Feringa, Adv. Synth. Catal. 2002, 344, 1003.

[6] M. van den Berg, A.J. Minnaard, B. Feringa, J.G. de Vries (DSM NV), WO 02/04466-A2, 2002.

[7] a) L.B. Wolf, T. Sonke, K.C.M.F. Tjen, B. Kaptein, Q.B. Broxterman, H.E. Schoemaker, F.P.J.T. Rutjes, Adv. Synth. Catal. 2001, 343, 662; b) F.P.J.T. Rutjes, L.B. Wolf, H.E. Schoemaker, J. Chem. Soc. Perkin Trans. 1 2000, 4197.

[8] S. Torrii, H. Okumoto, T. Kotani, F. Akahoshi, Chem. Lett. 1989, 1971.

[9] M.P. Jennings, E.A. Cork, P.V. Ramachandran, J. Org. Chem. 2000, 65, 8763. 